\title{
Computationally Efficient Procedure for Stress Analysis of Laminated Composite Shell Subjected to Different Loading Using ABAQUS Software
}

\author{
Appaso M. Gadade ${ }^{1 *}$, Mahesh Sutar ${ }^{2}$ \\ ${ }^{1}$ Mechanical Engineering Department, Thapar Institute of Engineering and Technology, Patiala 147004, India \\ ${ }^{2}$ Mechanical Engineering Department, Army Institute of Technology, Pune 411015, India
}

Corresponding Author Email: appaso.gadade@ @ thapar.edu

https://doi.org/10.18280/rcma.300206

Received: 28 November 2019

Accepted: 15 February 2020

\section{Keywords:}

polymer matrix composites, layered shell panel, finite element analysis, modeling and simulation, deformation analysis

\begin{abstract}
The purpose of this study is to develop finite element model for accurate estimation of deflection and stresses of a laminated shell panel using student version of commercial software ABAQUS. The results are obtained in terms of stress and deflection of laminated composite shell for different lamination scheme, lamination type, boundary conditions, aspect ratios, loading conditions and orthotropic ratios. The various boundary conditions used in the present analysis are clamped-clamped (CCCC), hinged-hinged (HHHH), clamped-hinged (CHCH), clamped-free (CFCF) and simply supported (SSSS). The different loading conditions used are sinusoidal loading and uniformly distributed loading. The results obtained using present finite element model is compared with the results of various literature for ensuring accuracy, efficacy and economy. The validation study shows good agreement between present results and existing results. As student version of ABAQUS is used to evaluate the results, it has reduced computational efforts and computational cost.
\end{abstract}

\section{INTRODUCTION}

Composite laminates are an assembly of layers of fibrous composite materials which can be stacked together to provide required engineering properties such as elastic moduli, Poison's ratio, including in-plane stiffness, bending stiffness, strength, and coefficient of thermal expansion. The popularity of composite material shell panel is increasing day-by-day due to its light weight, high stiffness to weight ratio and excellent structural tailoring capabilities. Composite shell structures are widely used in aerospace components (tails, wings, fuselages, propellers), space, boat and scull hulls, bicycle frames, racing car bodies and military applications. The use of laminated composite materials in the various structural applications has resulted in a significant increase in payload, weight reduction, speed, maneuverability and durability. For the accurate life prediction of these structures and extracting maximum available strength due to safety concerns, highly economic stress computation models are a need of today's mechanical engineering design community. The complexity arise due to anisotropic nature and geometry of laminated composite shell panel requires in depth knowledge of various theories as per the change of aspect ratios like Classical Lamination Theory (CLT), First order Shear Deformation Theory (FSDT) and Higher order Shear Deformation Theory (HSDT) and available in wide range of literature. Also, some commercial software is developed based on these theories like ABAQUS, ANSYS and NASTRAN to study finite element analysis of laminated composite shell structures.

Zukas and Vinson [1] developed a theory for stress analysis of pyrolytic-graphite type circular and cylindrical shell subjected to thermo-mechanical loadings, different than classical thin shell theory which includes effects of transverse shear deformation, transverse isotropy and thermal expansion through shell thickness. Lakshminarayana [2] used laminated anisotropic shell theory for the stress and deflection analysis of the axisymmetric cylinder-cone and cylinder geodesicisotensoid dome junction based on finite element displacement method. Reddy [3] developed a generalized firstapproximation shell theories accounting for shear deformations based on a shear deformable finite element and presented numerical results for the bending of layered, anisotropic, composite shells. The exact solution proposed by Ren [4] for laminated cylindrical shells in cylindrical bending proves that the classical shell theory leads to very poor results at low curvature radius-to-depth ratios, but it converges to the exact solutions as the ratio increases. The dynamic response of laminated composite shell subjected to inelastic impact is obtained by Lin and Lee [5] using a modified isoparametric linear shell element where the shear deformation and rotary inertia is taken into account. Sadatos and Timarci [6] introduced certain general functions of the transverse coordinate into shell displacement approximation accounting for the inclusion of the transverse shear deformation effects into the theoretical unification of the variationally consistent classical and shear deformation cylindrical shell theories. Wung [7] presented first-order shear and fourth-order transverse deformation theory for layered composite shells based on nonlinear degenerated 3D finite element model with a stress-strain enhancement technique by satisfying identically the nonzero surface boundary conditions and the interlaminar shear stress continuity conditions. Kant and Khare [8] presented $C^{0}$ continuity finite element formulation based on flat faceted element on a higher order displacement field for 
the stress and deflection analysis of thin-to-thick fibre reinforced composite laminated shells. Park et al. [9] presented a finite element model of 4-node stress resultant shell element for the stress and deflection analysis of thin to moderately thick composite shells using interrelated displacement and rotation interpolations. Khosravi et al. [10] developed an efficient finite element procedure for the geometrically nonlinear analysis of laminated composite shell using facetbased shell element based on the corotational approach. Kwon [11] implemented a multiscale analysis technique to the shell element formulation for the computation of the stress and strain at fibre and matrix level by using a solid like shell element. $\mathrm{Xu}$ [12] computed stress values on every play and every node ordered by the X-coordinate using threedimensional finite element shell model in PATRAN. Payette and Reddy [13] implemented a novel seven parameter continuum shell finite element formulation using general quadrilateral finite elements based on high-polynomial order spectral/hp functions. Patel [14] obtained bending response of geometrically nonlinear laminated composite shell panel subjected to bending loading by using eight node degenerated shell elements with five degrees of freedom per element. Gadade et al. [15-17] recently used HSDT for computation of deformation, stress and failure of laminated composite plate. Rao et al. [18] buckling of conical shell subjected to uniform external pressure using theoretical and numerical approach. Taqi and Gadade [19] obtained static response of laminated composite shell panel under transverse loading using MATLAB based numerical approach. Suryawanshi and Gadade [20] obtained response of laminated composite cylindrical shell using higher order shear deformation theory.

Above literature review clearly establishes a fact that due to anisotropic nature and geometric complications accurate computation of stresses and deflection plays vital role in strength prediction. In this paper, a simple and computationally efficient finite element procedure is developed for accurate evaluation of stresses and deflection of laminated composite shell panels subjected to different loading and boundary conditions by using a student version of ABAQUS. The results are obtained for the laminated composite shell under different loading and boundary condition for different aspect ratios and orthotropic ratios.

The remainder of this paper is organized as follows: Section 2 describes step-by-step procedure adopted for solving this problem, Section 3 describes results for various geometrical, loading and boundary conditions and Section 4 provides conclusions of this study.

\section{GENERAL PROCEDURE}

Laminated composite shell considered in the present study is modeled in a student version of ABAQUS 6.14 software. The procedure followed for accurate computation of stresses and deflection is as mentioned below:

(1) Modeling of shell geometry.

(2) Define material properties for a composite lamina.

(3) Create and modify lamination scheme for laminate.

(4) Assembly of lamina.

(5) Apply loading and boundary conditions.

(6) Apply appropriate meshing to the shell geometry.

(7) Start simulation for evaluating results

(8) Compilation of results for plotting
The detailed procedure used for the deformation and stress analysis of laminated composite shell subjected to different loading and boundary conditions is shown in a flowchart as shown in Figure 1.

Figure 2 shows the finite element meshed model for laminated composite cylindrical shell obtained by adopting a detailed procedure as described in a flowchart. A conventional shell type element with three degrees of freedom and Simpson integration rule is used for the modeling of composite shell. An independent mesh is used for the meshing of the geometry of shell.

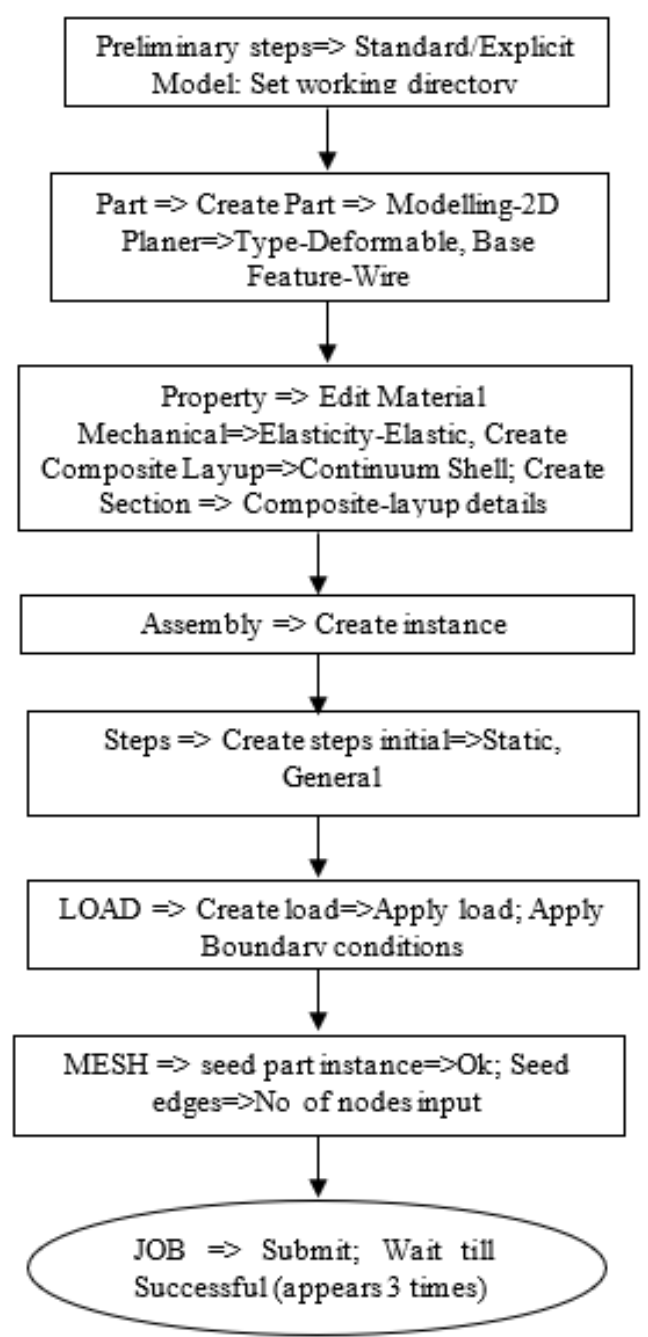

Figure 1. Flow-chart for the procedure of ABAQUS (Student Version) for the modeling and analysis of laminated composite cylindrical shell

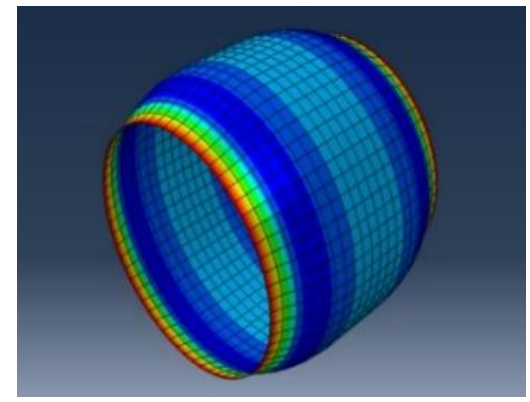

Figure 2. Finite element meshed model for laminated composite cylindrical shell 


\section{RESULTS AND DISCUSSION}

In the present study, various examples are considered for the validation of accuracy and efficacy of the finite element procedure adopted for computing deflection and stresses of laminated composite shell subjected to different loading conditions. A typical laminated composite cylindrical shell with radius $R$ and width $a$, having its axis along $y$-axis of Cartesian coordinate system and consisting of different lamina oriented in different directions is shown in Figure 3.

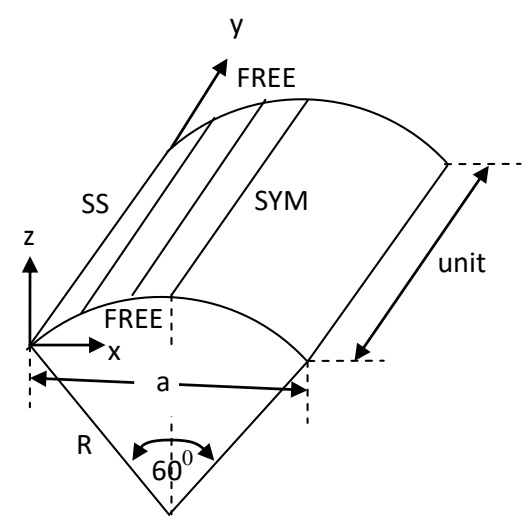

Figure 3. Geometry of laminated composite cylindrical shell with FEM idealization

\subsection{Validation study}

An accuracy and efficacy the present finite element analysis procedure is ensured by comparing deflection and stresses obtained with the results available in the various literatures.

Table 1 shows material properties and geometric parameters used for the validation of deflection of cylindrical shell subjected to non-dimensional internal pressure $P_{0}=6.41 / \pi$, with the same shown in Reddy [21].

Table 1. Material properties and geometric parameters for cylindrical shell subjected to internal pressure [21]

\begin{tabular}{cc}
\hline Properties & Value \\
\hline$E_{1}$ & $51.71 \mathrm{GPa}$ \\
$E_{2}$ & $13.789 \mathrm{GPa}$ \\
$G_{12}$ & $8.618 \mathrm{GPa}$ \\
$G_{13}=G_{23}$ & $4.309 \mathrm{GPa}$ \\
$v_{12}$ & 0.25 \\
Radius $(R)$ & $508 \mathrm{~mm}$ \\
Length $(a)$ & $508 \mathrm{~mm}$ \\
Thickness $(h)$ & $25.4 \mathrm{~mm}$ \\
\hline
\end{tabular}

Table 2. Validation for radial deflection $w$ of laminated composite cylindrical shell $\left[0^{\circ}\right]$ and $\left[0^{\circ} / 90^{\circ}\right]$ subjected to internal pressure and clamped at all the edges with Reddy [21]

\begin{tabular}{ccc}
\hline Laminate & \multicolumn{2}{c}{ Radial deflection, $\boldsymbol{w}$} \\
\hline & Present & Reddy [21] \\
\hline$\left[0^{0}\right]$ & 0.35 & 0.37 \\
{$\left[0 / 90^{0}\right]$} & 0.16 & 0.18 \\
\hline
\end{tabular}

Table 2 shows the validation of radial deflection of laminated composite shell $\left[0^{\circ}\right]$ and $\left[0^{\circ} / 90^{\circ}\right]$ with Reddy subjected to radial internal pressure and clamped at all the edges. The result shows good agreement with the results of
Reddy [21]. The variation in the deflection is observed because Reddy has used finite element formulation based on Classical thin shell theory which doesn't account for the shear stresses.

Table 3 shows material properties and geometric parameters used for the validation of radial deflection $(w)$ and stresses $\left(\sigma_{x}\right)$ of laminated composite cylindrical shell with the deflection and stresses of Ren [4]. Table 4 shows the comparison of radial deflection and stresses of laminated cylindrical shell obtained by present finite element procedure with that of Ren [4]

Table 3. Material properties and geometric parameters for cylindrical shell subjected to internal pressure [4]

\begin{tabular}{cc}
\hline Properties & Value \\
\hline$E_{1}$ & $172.368 \mathrm{GPa}$ \\
$E_{2}$ & $6.894 \mathrm{GPa}$ \\
$G_{12}$ & $1.378 \mathrm{GPa}$ \\
$G_{13}=G_{23}$ & $3.447 \mathrm{GPa}$ \\
$v_{12}=v_{23}=v_{13}$ & 0.25 \\
Radius $(R)$ & $254 \mathrm{~mm}$ \\
\hline
\end{tabular}

Table 4. Validation for non-dimensional radial deflection $w$ and normal stress $\left(\sigma_{x}\right)$ of laminated composite cylindrical shell for $\left[0^{\circ}\right],\left[90^{\circ} / 0^{\circ}\right],\left[0^{\circ} / 90^{\circ} / 0^{\circ}\right]$ lamination scheme and subjected to transverse sinusoidal loadings with Ren [21]

\begin{tabular}{ccccc}
\hline & \multicolumn{2}{c}{ Radial deflection, $\boldsymbol{w}$} & \multicolumn{2}{c}{ Stress $\left(\boldsymbol{\sigma}_{\boldsymbol{x}}\right)$} \\
\cline { 2 - 5 } $\boldsymbol{R} / \boldsymbol{h}$ & Present & Ren [4] & Present & Ren [4] \\
\hline \multicolumn{4}{c}{ Unidirectional cylindrical shell $\left[0^{\circ}\right]$} \\
\hline 2 & 0.8126 & 0.9986 & 1.766 & 1.907 \\
4 & 0.2917 & 0.3120 & 1.052 & 1.079 \\
10 & 0.0928 & 0.1150 & 0.791 & 0.807 \\
50 & 0.0701 & 0.0770 & 0.694 & 0.752 \\
100 & 0.0792 & 0.0755 & 0.714 & 0.751 \\
\hline \multicolumn{4}{c}{ Bidirectional cylindrical shell [90\% $\left.0^{\circ}\right]$} \\
\hline 2 & 2.0321 & 2.079 & 2.016 & 2.254 \\
4 & 0.7927 & 0.854 & 2.103 & 2.190 \\
10 & 0.4841 & 0.493 & 2.026 & 2.153 \\
50 & 0.4004 & 0.409 & 2.091 & 2.110 \\
100 & 0.4001 & 0.403 & 2.121 & 2.125 \\
\hline \multicolumn{5}{c}{$3-$ ply cylindrical shell $\left[0^{\circ} / 90^{\circ} / 0^{\circ}\right]$} \\
\hline 2 & 1.1529 & 1.4360 & 2.272 & 2.463 \\
4 & 0.3028 & 0.4570 & 1.295 & 1.367 \\
10 & 0.0918 & 0.1440 & 0.809 & 0.897 \\
50 & 0.0724 & 0.0808 & 0.713 & 0.782 \\
100 & 0.0711 & 0.0787 & 0.765 & 0.781 \\
\hline \multicolumn{4}{c}{}
\end{tabular}

The deformation and stress results are obtained for unidirectional $\left[0^{\circ}\right]$, bi-directional $\left[90^{\circ} / 0^{\circ}\right]$ and 3-ply $\left[0 \% / 90^{\circ} / 0^{\circ}\right]$ cylindrical shell. The ratio of $\operatorname{radius}(R)$ and thickness $(h)$ is known as aspect ratio and in this validation study it is to be taken as 2, 4, 10, 50 and 100. The boundary conditions used are simply supported at both the edges and a transverse sinusoidal loadings applied is given by:

$$
q=q_{0} \sin \left(\frac{\pi x}{a}\right)
$$

where, $q_{0}=1, x$ and $a$ are shown in Figure 3.

The non-dimensionalized form of radial deflection $(w)$ and stress $\left(\sigma_{x}\right)$ obtained in the present work can be represented as

$$
w=\frac{10 E_{2} w_{0}}{q_{0} h S^{4}}
$$




$$
\sigma_{x}=\frac{\sigma_{x 0}}{q_{0} S^{2}}
$$

where, $S=R / h, E_{2}=$ elastic modulus, $h=$ thickness of cylindrical wall of shell, $q_{0}=$ load parameter, $w_{0}=$ radial deflection and $\sigma_{x}$ =stress obtained by ABAQUS. It is observed from the results that the present results obtained by using student version of ABAQUS under predicts deflection as well as stresses as compared to the results of literature. This clearly indicates that the HOST handles shear deformation as well as stresses very well as compared to ABAQUS but with higher computational time and complexity.

\subsection{Effect of different lamination types, loading and boundary conditions}

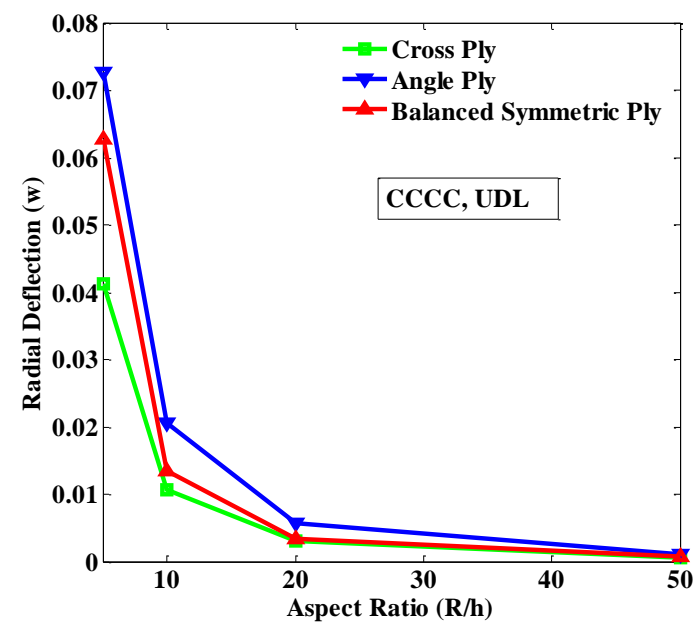

(a)

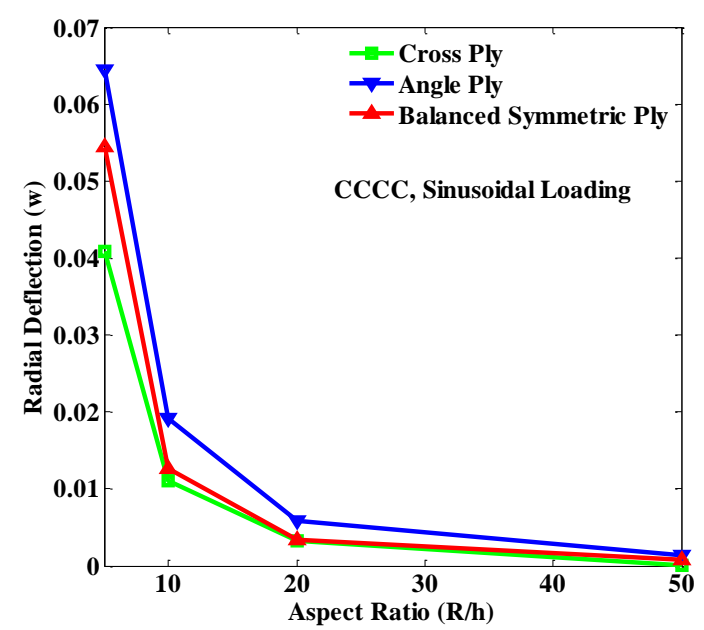

(b)

Figure 4. Effect of different aspect ratios $(R / h)$ on radial deflection $(w)$ of laminated composite cylindrical shell with different lamination schemes clamped at all the edges (CCCC) and subjected to (a) uniformly distributed loadings

(UDL) (b) sinusoidal loadings. heat sources

The effect of different lamination types such as cross ply $\left[0^{\circ} / 0^{\circ} / 90^{\circ} / 90^{\circ} / 90^{\circ} / 90^{\circ} / 0^{\circ} / 0^{\circ}\right]$, angle ply $\left[45^{\circ} / 45^{\circ} /-45^{\circ} /-45^{\circ} /-45^{\circ} \%\right.$ $\left.45^{\circ} / 45^{\circ} / 45^{\circ}\right]$ and balanced symmetric ply $\left[0^{\circ} / 45^{\circ} / 45^{\circ} / 90^{\circ} / 90^{\circ} /\right.$ $45^{\circ} / 45^{\circ} / 0^{\circ}$ ] on radial deflection and stresses for Uniformly Distributed Loadings (UDL) and sinusoidal loadings is examined in this section. The boundary conditions considered are Clamped-Clamped (CCCC), Clamped-Fixed (CFCF) and simply supported (SSSS). The material and geometric properties of the laminated composite cylindrical shell is shown in Table 3 . The results are obtained for different aspect ratios $(R / h)$ such as $5,10,20$ and 50 . This will enable to judge the effectiveness of present finite element procedure over thin to thick shells. The non-dimensional radial deflection $(w)$ and stress $\left(\sigma_{x}\right)$ as shown in Eq. (2) and (3) is obtained for various conditions.

Figure 4 shows the effect of different aspect ratios on nondimensionalised radial deflection ( $w$ ) of laminated composite cylindrical shell fixed at all the edges and subjected to $(a)$ uniformly distributed load and $(b)$ sinusoidal loading for cross ply, angle ply and balanced symmetric ply lamination types. It is observed from the results that the angle ply laminates undergoes more deflection as compared to cross ply and balanced symmetric ply laminate for the same amount of loadings. If the load is changed from UDL to sinusoidal loading the radial deflection will be less as shown in Figure 4 (b), but the trend of lamination types remains same.

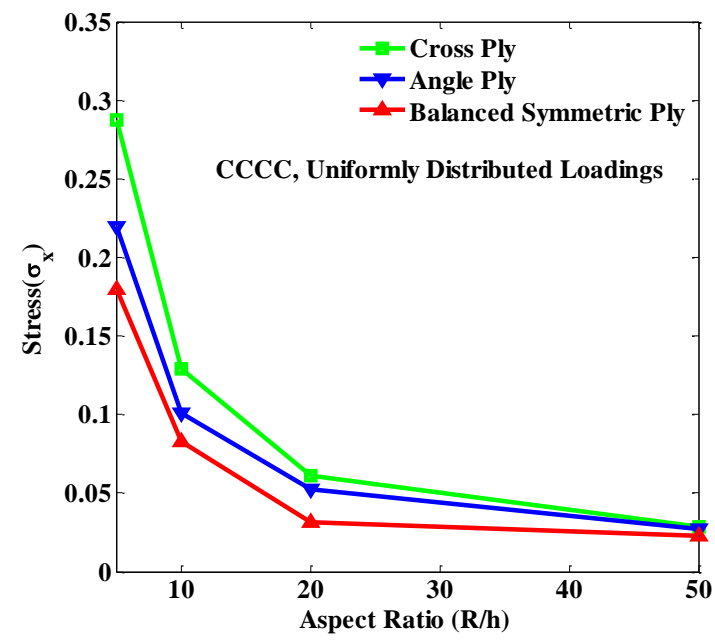

(a)

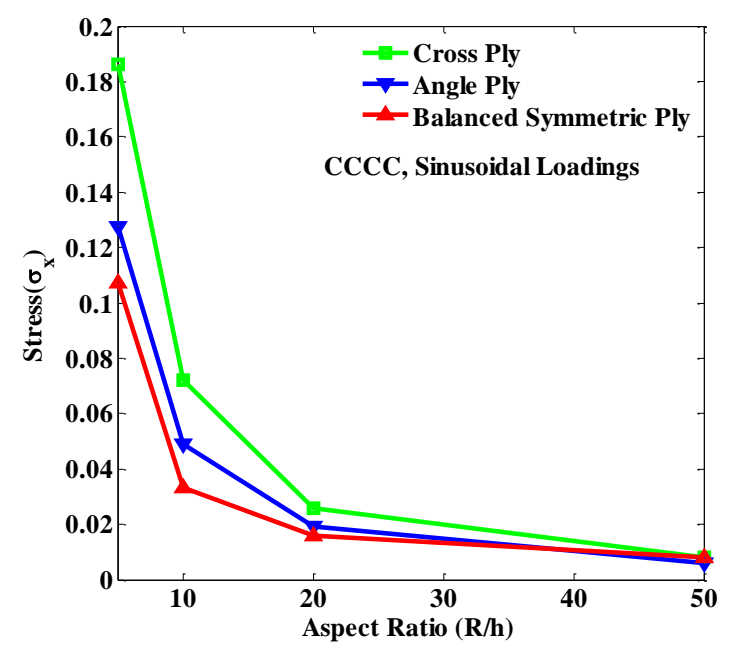

(b)

Figure 5. Effect of different aspect ratios $(R / h)$ on stress $\left(\sigma_{\mathrm{x}}\right)$ of laminated composite cylindrical shell with different lamination schemes clamped at all the edges (CCCC) and subjected to $(a)$ uniformly distributed loadings (UDL) (b) sinusoidal loadings 
Figure 5 shows the effect different aspect ratios on nondimensionalised stress $\left(\sigma_{x}\right)$ of laminated composite shell fixed at all the edges and subjected to (a) uniformly distributed load and (b) sinusoidal loading for cross ply, angle ply and balanced symmetric ply lamination types. It is observed from the results that the cross ply laminates undergoes more stress as compared to angle ply and balanced symmetric ply laminates under uniformly distributed loadings. For sinusoidal loading under similar conditions the stress induced in the laminated cylindrical shell is less and the trend across various lamination types remains same as shown in Figure 5 (b).

Figure 6 (a) and (b) shows the variation of nondimensionalised radial deflection $(w)$ with the different aspect ratio $(R / h)$ for clamped-fixed $(\mathrm{CFCF})$ laminated cylindrical shell subjected to uniform loadings for sinusoidal loadings respectively. It is observed from the results that the angle ply laminates deforms more as compared to cross ply and balanced symmetric ply for both the loading conditions.

Figure 7 (a) and (b) shows the variation of nondimensionalised stresses $\left(\sigma_{\mathrm{x}}\right)$ for laminated composite cylindrical shell with clamped-fixed (CFCF) boundary conditions and subjected to uniformly distributed and sinusoidal loadings respectively. It is observed from the results that the balanced ply undergoes more stress as compared to cross ply and angle ply laminates for both the loading conditions.

Figure 8 (a) and (b) shows the variation of non-dimensional radial deflection $(w)$ of laminated composite cylindrical shell with the aspect ratio $(R / h)$ for simply supported boundary conditions (SSSS) subjected to uniform and sinusoidal loadings. It is observed from the results that the angle ply deforms more as compared to cross ply and balanced symmetric ply laminates.

Figure 9 (a) and (b) shows the variation of the nondimensional stress $\left(\sigma_{\mathrm{x}}\right)$ induced in the laminated cylindrical shell with simply supported boundary conditions subjected to uniformly distributed and sinusoidal loadings respectively. It is observed from the results that the cross-ply laminates induce more stress as compared to the angle ply and the balanced ply laminates for both the loading conditions.

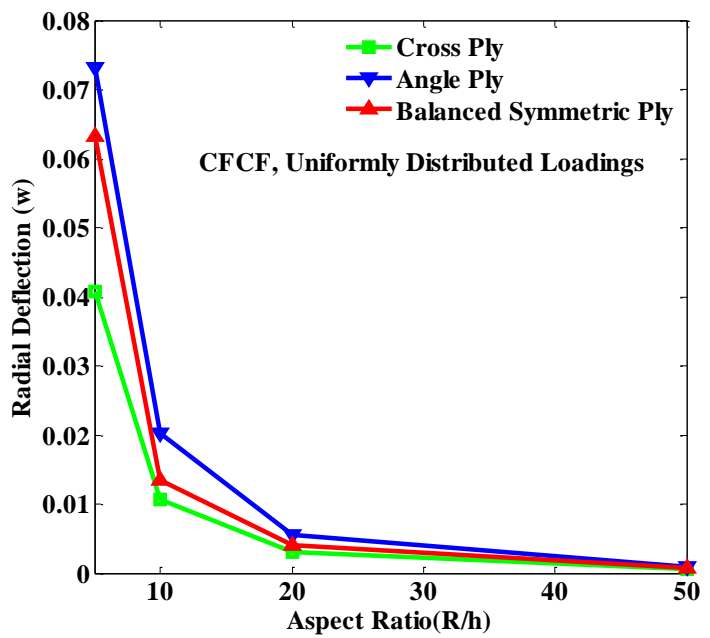

(a)

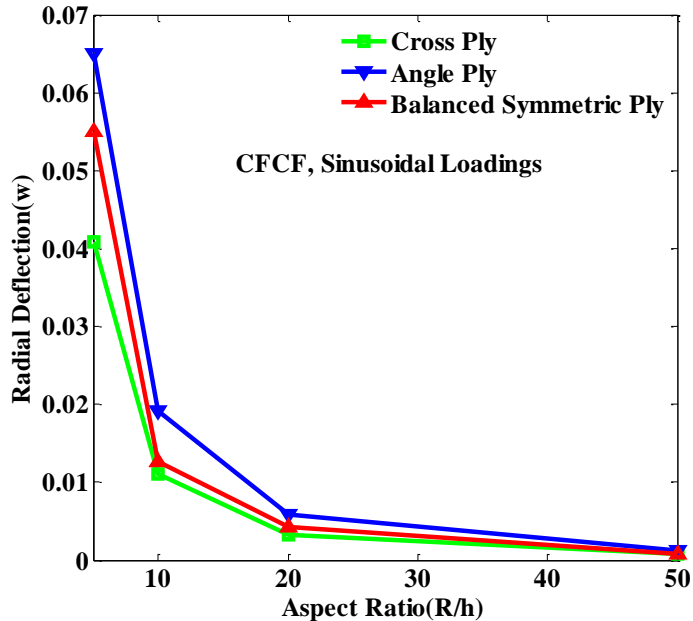

(b)

Figure 6. Effect of different aspect ratios $(R / h)$ on radial deflection $(w)$ of laminated composite cylindrical shell with different lamination schemes, clamped-fixed (CFCF) boundary conditions and subjected to $(a)$ uniformly distributed loadings (UDL) ( $b$ ) sinusoidal loadings

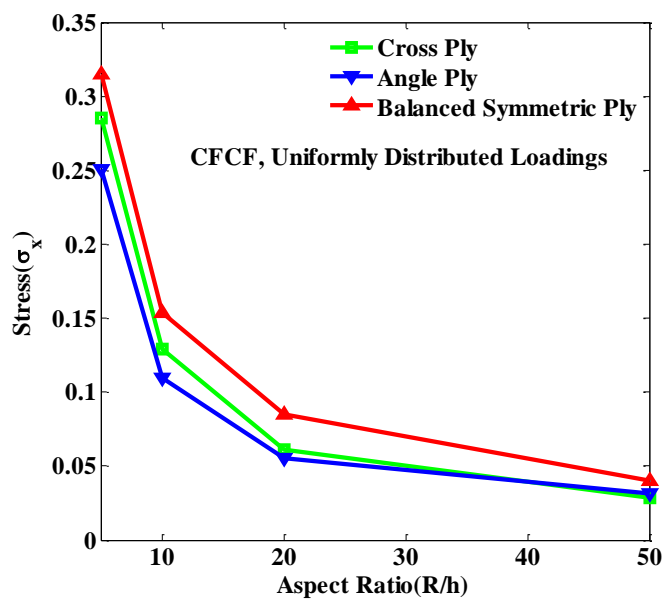

(a)

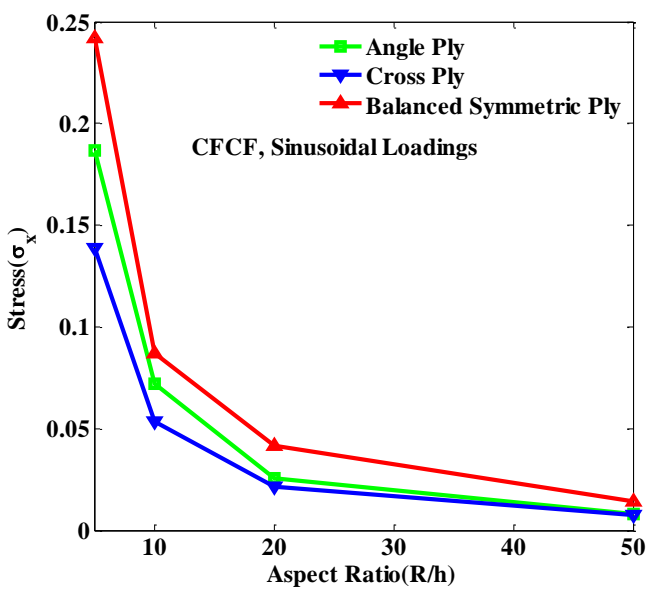

(b)

Figure 7. Effect of different aspect ratios $(R / h)$ on stress $\left(\sigma_{\mathrm{x}}\right)$ of laminated composite cylindrical shell with different lamination schemes, clamped -Fixed (CFCF) boundary conditions and subjected to $(a)$ uniformly distributed loadings $(U D L)(b)$ sinusoidal loadings 


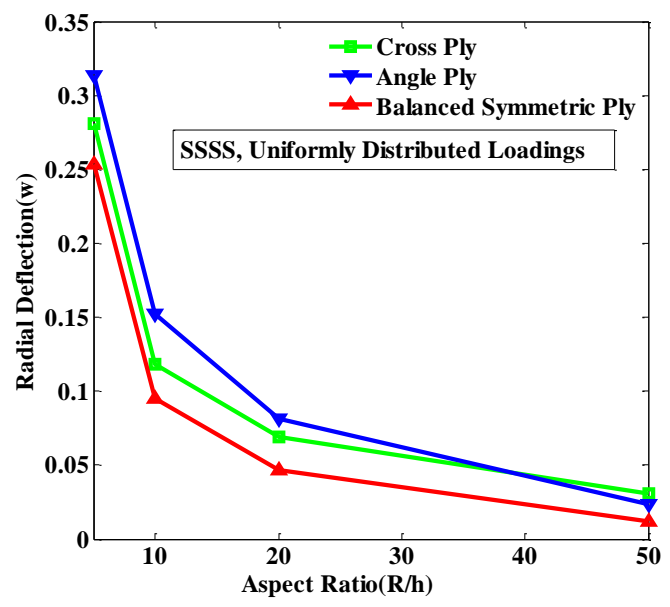

(a)

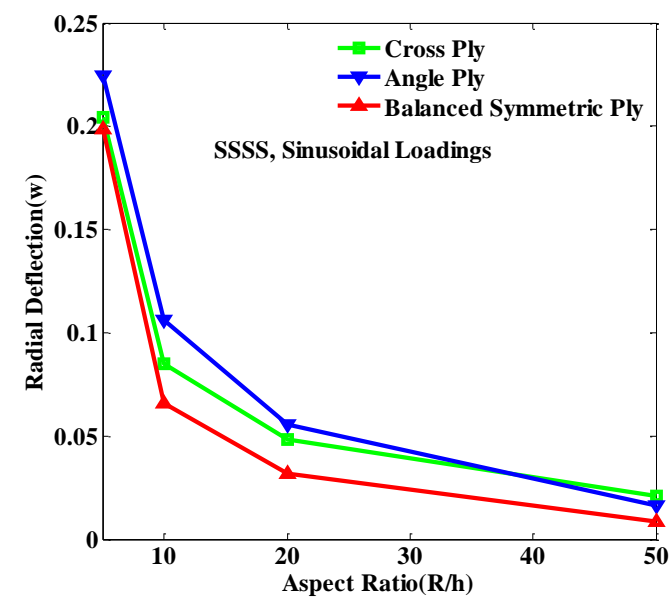

(b)

Figure 8. Effect of different aspect ratios $(R / h)$ on radial deflection $(w)$ of laminated composite cylindrical shell with different lamination schemes, simply supported (SSSS) boundary conditions and subjected to $(a)$ uniformly distributed loadings (UDL) ( $b$ ) sinusoidal loadings

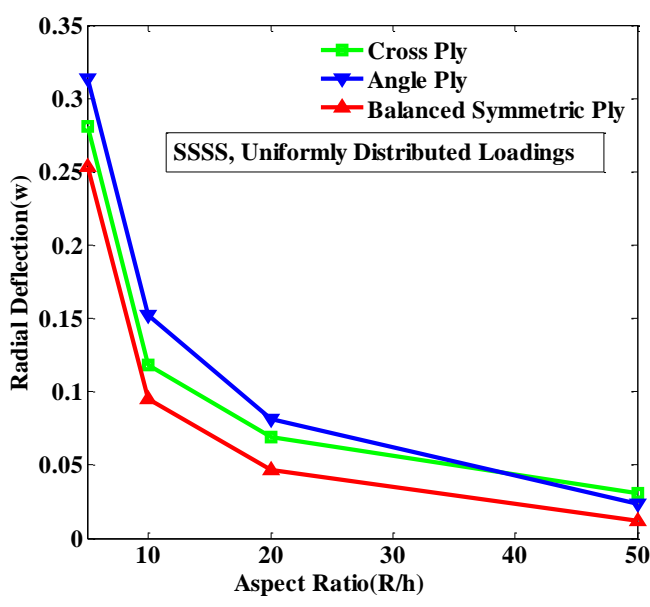

(a)

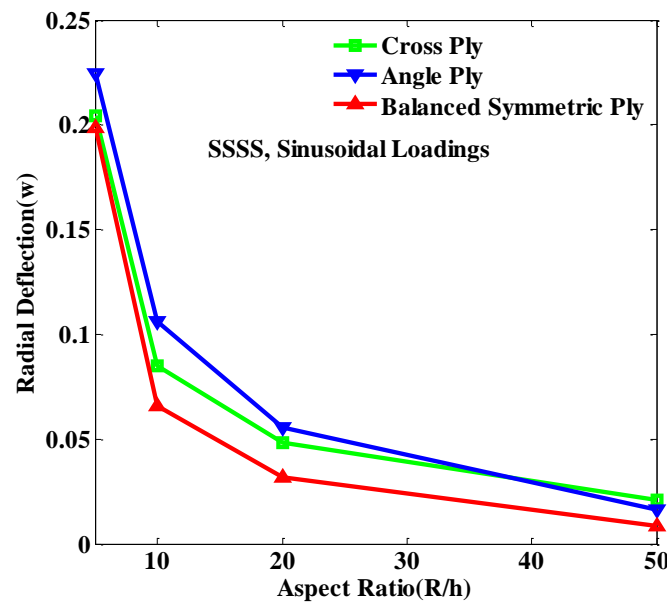

(b)

Figure 9. Effect of different aspect ratios $(R / h)$ on stress $\left(\sigma_{\mathrm{x}}\right)$ of laminated composite cylindrical shell with different lamination schemes, simply supported (SSSS) boundary conditions and subjected to $(a)$ uniformly distributed loadings (UDL) (b) sinusoidal loadings

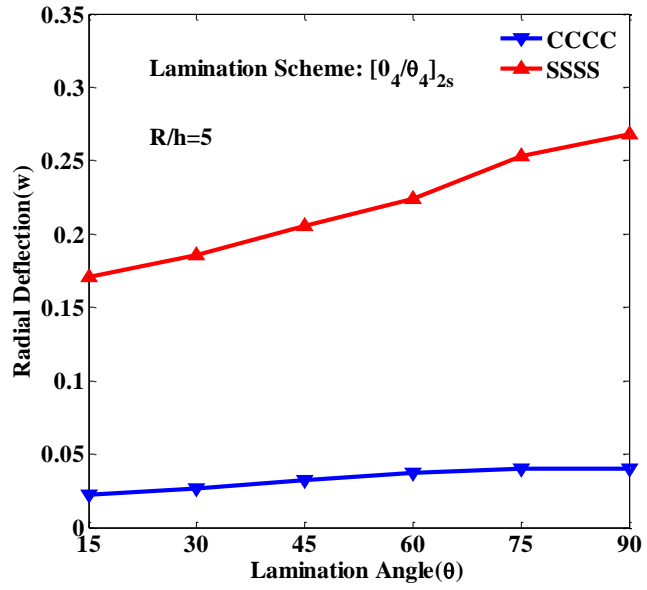

(a)

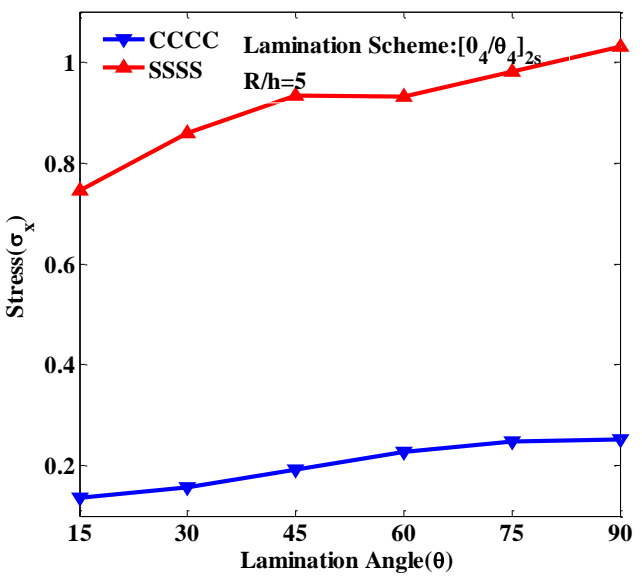

(b)

Figure 10. Effect of lamination angle $(\theta)$ on $(a)$ radial deflection $(w)(b)$ stress $\left(\sigma_{\mathrm{x}}\right)$ of laminated composite cylindrical shell subjected to uniformly distributed loadings with different boundary conditions $(R / h=5)$ 


\subsection{Effect of different lamination angle}

The effect of lamination angle on non-dimensional radial deflection and stress for laminated composite cylindrical shell subjected to uniformly distributed loadings is presented in this section. The all edges clamped (CCCC) and simply supported (SSSS) boundary conditions are considered for the analysis. The lamination scheme considered is $\left[0_{4} / \theta_{4}\right]_{2 s}$ for the analysis. A laminated composite shell with aspect ratio $(\mathrm{R} / \mathrm{h})=5$ is considered for this study. The material properties and geometrical conditions considered in the previous section used in this section also.

Figure 10 (a) and (b) shows the effect of lamination angle on non-dimensional radial deflection and stress respectively, for laminated composite cylindrical shell. It is observed from the results that the simply supported (SSSS) boundary conditions shows more deflection and stresses for higher lamination angle than the clamped-clamped (CCCC) boundary conditions. The common trend observed for both the boundary conditions is that the deflection as well as stresses increases with the lamination angle. This clearly indicates that the present finite element analysis procedure helps to achieve sufficient accuracy for stress and deformation computation by using cheapest computational resource student version of ABAQUS 6.14. This will be helpful in the robust design of structures made up of laminated composite shell as a building block.

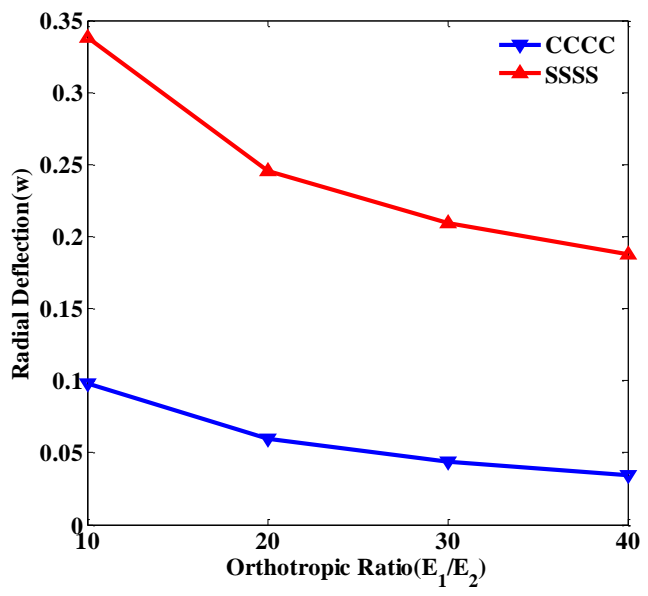

(a)

\subsection{Effect of orthotropic ratio $\left(E_{1} / E_{2}\right)$}

The degree of anisotropy present in a laminated composite structure is judged by the ratio of two elastic moduli ( $E_{l}$ and $E_{2}$ ). The laminated composites are known for its anisotropic nature and it is necessary to study its effect on the response of the laminated composite cylindrical shell in terms of radial deflection and stresses subjected to mechanical loadings.

Figure 11 (a) and (b) shows the variation of nondimensional radial deflection and stresses with the change in orthotropic ratio for laminated composite cylindrical shell subjected to uniformly distributed loadings. The same material properties and geometrical parameters are used in this section as shown in the previous section. The radial deflection and stress is non-dimensionalised by using Eqns. (2) and (3) respectively. The clamped-clamped (CCCC) and simply supported (SSSS) boundary conditions are used for examining the effect of orthotropic ratio.

It is observed from the results that if the laminated composite shell in the present study is clamped at all the edges (CCCC boundary conditions) get more deformed when subjected to internal pressure than simply supported at all the edges (SSSS boundary conditions). The similar trend is observed for the stresses induced. It is also observed from the results that the radial deflection decreases and stresses increases with orthotropic ratio for both the boundary conditions.

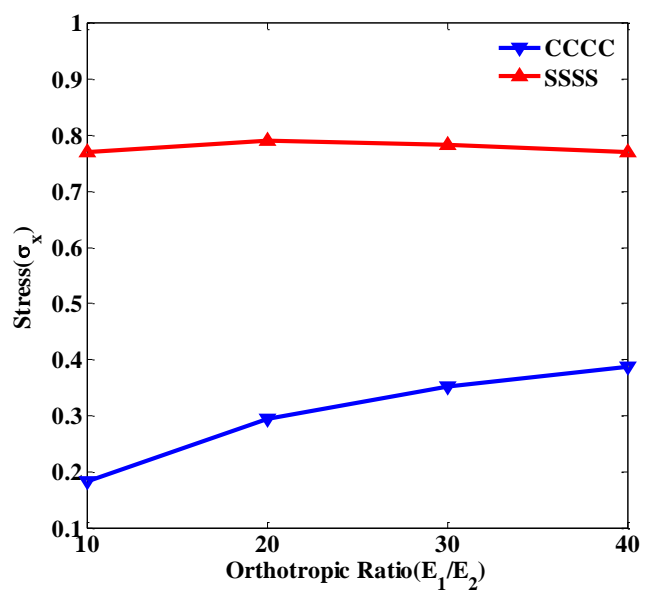

(b)

Figure 11. Effect of orthotropic ratio $\left(E_{l} / E_{2}\right)$ on $(a)$ radial deflection $(w)(b)$ stress $\left(\sigma_{\mathrm{x}}\right)$ of laminated composite cylindrical shell subjected to uniformly distributed loadings with different boundary conditions $(R / h=5)$

\section{CONCLUSIONS}

A student version of ABAQUS software is evaluated for its computational efficacy for a challenging problem of laminated composite shell. A laminated composite shell modeled successfully and its response under uniformly distributed and sinusoidal loading is examined for clamped-clamped (CCCC), clamped-fixed (CFCF) and simply supported (SSSS) boundary conditions. The response of laminated composite shell in terms of radial deflection and stresses is computed by using present computationally efficient finite element analysis procedure and compared with the similar results available in various literature obtained by using some advanced approaches like HOST and FOST for its accuracy and efficacy.

It is observed from the comparison that the present approach shows fairly good agreement with the results of literatures.
It is also observed from this limited study that the present approach gives poor results for thick laminates as compared to thin laminates. This clearly indicates that the student version of ABAQUS requires some shear correction factor for more accurate analysis. This model is extended for computing progressive failure and fracture of laminated composite shell panel as a future study.

\section{REFERENCES}

[1] Zukas, J.A., Vinson, J.R. (1971). Laminated transversely isotropic cylindrical shells. Journal of Applied Mechanics, 38(2): 400-407. https://doi.org/10.1115/1.3408789

[2] Lakshminarayana, H.V. (1976). Finite element analysis 
of laminated composite shell junctions. Computers and Structures, 6(1): 11-15. https://doi.org/10.1016/00457949(76)90068-7

[3] Reddy, J.N. (1982). Bending of laminated anisotropic shells by a shear deformable finite element. Fibre Science and Technology, 17(1): 9-24. https://doi.org/10.1016/0015-0568(82)90058-6

[4] Ren, J.G. (1987). Exact solutions for laminated cylindrical shells in cylindrical bending. Composite Science and Technology, 29(3): 169-187. https://doi.org/10.1016/0266-3538(87)90069-8

[5] Lin, H.J., Lee, Y.J. (1990). On the inelastic impact of composite laminated plate and shell structures. Composite $\quad$ Structures, 14(2): 89-111. https://doi.org/10.1016/0263-8223(90)90025-A

[6] Soldatos, K.P., Timarci, T. (1993). A unified formulation of laminated composite, shear deformable, five-degreesof-freedom cylindrical shell theories. Composite Structures, 25(1-4): 165-171. https://doi.org/10.1016/0263-8223(93)90162-J

[7] Wung, P.M. (1997). Laminated composite structures by continuum-based shell elements with transverse deformation. Computers and Structures, 62(6): 10731090. https://doi.org/10.1016/S0045-7949(96)00324-0

[8] Kant, T., Khare, R.K. (1997). A higher-order facet quadrilateral composite shell element. International Journal of Numerical Methods in Engineering, 40: 4477 $4499 . \quad \mathrm{https} / / /$ doi.org/10.1002/(SICI)10970207(19971230)40:24<4477::AID-NME229>3.0.CO;23

[9] Park, T., Kim, K., Han, S. (2006). Linear static and dynamic analysis of laminated composite plates and shells using a 4-node quasi-conforming shell element, Composite Part-B, 37(2-3): 237-248. https://doi.org/10.1016/j.compositesb.2005.05.007

[10] Khosravi, P., Ganesan, R., Sedaghati, R. (2008). An efficient facet shell element for $\mathrm{C} 0$ rotational nonlinear analysis of thin and moderately thick laminated composite structures. Composite Structures, 86(9): 850858. https://doi.org/10.1016/j.compstruc.2007.04.010

[11] Kwon, Y.W. (2013). Analysis of laminated and sandwich composite structures using solid-like shell elements. Applied Composite Materials, 20:355-373. https://doi.org/10.1007/s10443-012-9273-8

[12] Xu, J., Dou, Li, C. D. (2012). Stress-based health assessment of composite open-end cylindrical laminated shell with stepped-lap repairs. Advanced Material
Research,

393-395: 297-303. https://doi.org/10.4028/www.scientific.net/AMR.393395.297

[13] Payette, G.S., Reddy, J.N. (2014). A seven-parameter spectral/hp finite element formulation for isotropic, laminated composite and functionally graded shell structures. Computational Methods Applied Mechanical Engineering, 278: 664-704. https://doi.org/10.1016/j.cma.2014.06.021

[14] Patel, S.N. (2015). Nonlinear finite element bending analysis of composite shell panels. Advances in Structural Engineering, 1: 137-145. https://doi.org/10.1007/978-81-322-2190-6 13

[15] Gadade, A.M., Lal, A., Singh, B.N. (2016). Accurate stochastic initial and final failure of laminated plates subjected to hygro-thermo-mechanical loadings using Puck's failure criteria. International Journal of Mechanical Sciences, 114: 177-206. https://doi.org/10.1016/j.ijmecsci.2016.05.015

[16] Gadade, A.M., Lal, A., Singh, B.N. (2016). Finite element implementation of Puck's failure criterion for failure analysis of laminated plate subjected to biaxial loadings. Aerospace Science and Technology, 55: $227-$ 241. https://doi.org/10.1016/j.ast.2016.05.001

[17] Gadade, A.M., Lal, A., Singh, B.N. (2016). Stochastic progressive failure analysis of laminated composite plate using Pucks failure criteria. Mechanics of Advanced Materials and Structures, 23(7): 739-757. https://doi.org/10.1016/j.ast.2016.05.001

[18] Rao, S.S., Rao, M. (2019). Buckling study of conical Shells subjected to uniform pressure using theoretical and FEA approaches. Journal of Composite and Advanced Materials, 29(2): 119-123. https://doi.org/10.18280/rcma.290207

[19] Taqi, A., Gadade, A.M. (2019). Static response of laminated composite shells subjected to transverse loading. Materials Today: Proceedings, 16(2): 686-693. https://doi.org/10.1016/j.matpr.2019.05.146

[20] Suryawanshi, A., Gadade, A.M. (2019). Response of laminated composite cylindrical shell using higher order shear deformation theory. Journal of Physics: Conference $\quad$ Series, 1240: 012006. https://iopscience.iop.org/article/10.1088/17426596/1240/1/012006

[21] Reddy, J.N. (2004). Laminated Plates and Composite Shells. CRC Press, LLC, USA. 